\title{
Comparison of the conductive properties of polyester/viscose fabric treated with Cu nanoparticle and MWCNT $_{s}$
}

\author{
H. Akbarpour ${ }^{1} \cdot$ A. Rashidi ${ }^{2} \cdot$ M. Mirjalili ${ }^{1} \cdot$ A. Nazari $^{3}$
}

Received: 2 September 2019 / Accepted: 9 November 2019 / Published online: 30 November 2019

(c) The Author(s) 2019

\begin{abstract}
In this work, the specimen of the fabrics (polyester/viscose blend) was prepared. At first, the samples were placed under microwave radiation at different times, and then the optimum condition of treated fabrics $(8 \mathrm{~min})$ was selected for treatment. The physical properties and surface morphology of $\mathrm{Cu}$ nanoparticle and multi-wall carbon nanotubes (MWCNTs) with different percentages were measured using dispersing agent, washing performance, stability, and physical properties of the fabric. The image of surface morphology's specimens was also photographed by scanning electron microscopy (SEM). Afterwards, we measured the specimens' electrical conductivity properties, according to AATCC 2005-76 standards, and subsequently, $K / S, \% R$, and Lab value of specimens was analyzed using reflection spectrophotometer. In fact, the results indicated that optimum electrical resistivity, which was also the aim of the study, is $9 \%$ one weight of fabric (o.w.f.) nanoparticles on the fabric and that electrical resistivity for the values of $9 \%$ o.w.f. for CNT is slightly greater than $\mathrm{Cu}$.
\end{abstract}

Keywords Polyester/viscose $\cdot$ Multi-wall carbon nanotubes $\cdot \mathrm{Cu}$ nanoparticles $\cdot$ Conductivity

\section{Introduction}

Based on a number of studies, the electrical conductive textiles are demanded both for sensing utilizations and wearable electronics and smart textile applications [1-3], transferring data, monitoring, biomedical and medicine reduction, RF shielding, tissue engineering, super capacitor, battery, fuel cell, transistor, solar cell, organic light emitting diodes $\left(\mathrm{OLED}_{\mathrm{S}}\right)$ and electro-chromic utilizations. In fact, incorporating the electrically conductive substances into the joint

M. Mirjalili

Dr.mirjalili@iauyazd.ac.ir

H. Akbarpour

Hamid.akbarpour@iauyazd.ac.ir

A. Rashidi

Rashidi50@yahoo.com

A. Nazari

a.nazari@iauyazd.ac.ir

1 Department of Textile and Polymer Engineering, Yazd Branch, Islamic Azad University, Yazd, Iran

2 Department of Textile Engineering, Science and Research Branch, Islamic Azad University, Tehran, Iran

3 Department of Art and Architect, Yazd Branch, Islamic Azad University, Yazd, Iran textiles would enable fabricating the comfortable, flexible, and wearable conductive textiles with multi-functional features [1]. Actually, nano-technology is one of the novel areas with the expectation of having extensive applications in each science and technology like material sciences, mechanics, processing technology of the materials, optics, electronics, medication, aero-space, plastics, energy, and textiles. Although, this technology is still in its childhood, research proved that it could be a beneficial instrument for improvement of the textiles functions so that it has been attended widely. However, new utilization of the nanotechnology in the textiles would afford diverse features with the potentials for better and novel uses in the products $[4,5]$. A number of arts are existing for producing conductive fabrics which include coating metals, conducting polymers over the fabric surfaces, metallic salts films [6], and carbon derivatives [7] or polymeric film synthesis [8-10].

According to the studies, the phrase "smart textiles" represents extensive field of studies and products, which expand practicality and utility of the usual fabrics. In fact, textile materials such as the filaments and fibers, which yarn together with the knitted, woven or non-woven structures and can have interaction with the surrounding/users have been called the smart textiles. However, it has been found that converging the electronics and textiles, that is e-textiles, 
may be suitable to design the smart materials with the abilities of the performance various functions that are now observed in the non-flexible and rigid electronic products [6]. Electrical resistance of a material indicates how strongly the material opposes the flow of electric current through it. Based on the electrical resistance of the materials, conductive textiles can be classified into the following groups. (1) Insulators: these textile materials have electrical resistance greater than $10^{11} \mathrm{ohms}$. They do not allow the electrical current to flow through them. (2) Dissipaters: these textile materials have electrical resistance in the range of $10^{4}-10^{11}$ ohms. These textile materials do not allow accumulation of electrical charge on their surface. The dissipation increases as the moisture level in the textile increases. (3) Conductors: these are textiles materials with a resistance less than $10^{4}$ ohms. Such textile materials allow smooth passage of electric current [11]. However, much attention has been paid to the continuous fibers and or yarns consisting of carbon nanotubes (CNTs) because of the respective inherent capabilities for forming diverse macroscopic objects via a simple knitting and or weaving of the yarns or fibers [12]. As Bunshi Fugetsu et al. [13] discovered, the CNT-based dyestuffs can be procured via dispersion of the aggregates of the multiwall CNTs in water by blending the zwitterionic surfactants with the anionic surfactants. Then, we used a dye-printing procedure and immediately utilized CNTs to the polyester multifilament yarns for forming an electrically conductive layer on all filaments of the multi-filament yarn. Actually, the yarns, which have electrical resistivity in the range between $10^{3}$ and $10^{9} \mathrm{O} / \mathrm{cm}$, have been achieved. Notably, the ones with $10^{3} \mathrm{O} / \mathrm{cm}$ resistivity might be applied for forming the soft, flat, and portable electrical heaters via vertical weaving the yarns into the fabrics. In addition, the yarns with $10^{5} \mathrm{O} /$ $\mathrm{cm}$ resistivity might be utilized for antistatic clothing, and the $10^{9} \mathrm{O} / \mathrm{cm}$ yarns for brushes for photo-copying machines. Also, Azam Ali et al. [14] investigated the effects of the silver nitrate concentrations on the electrical conductivity. Moreover, $2 \mathrm{~g} / 200 \mathrm{~mL}$ provided reasonable levels of the electrical conductivity values. Additionally, numerous numbers of dips (i.e., 50-150) in silver nitrate solution have been used to control the amounts of the silver particles deposition. Based on the findings, the greater numbers of the dips generated dense network of the silver particles. Therefore, they led to the increased electrical conductivity. We then dealt with the analysis of the conductive fabrics usefulness for electro-magnetic shielding capability by coaxially transmitting line technique over a frequency range between $30 \mathrm{MHz}$ and $1.5 \mathrm{GHz}$. In another study, done by Ebrahim Beygi Chime and et al. [15], using carbon nanotubes and titanium dioxide, it was discovered that the electrical conductivity of polyethylene terephthalate (PET), due to the presence of carbon black $\left(\mathrm{CB}_{\mathrm{S}}\right)$ on the surface of the PET fabric, increases slightly. In this paper, it was also indicated that the distribution of nanoparticles of titanium dioxide and nano-carbon black with the use of sodium hypophosphite acid and citric acid works and improves the conductivity of the PET fabric. In this research, unlike other studies done on various fabrics, fibers and resources, measurement of electrical conductivity in a polyester/viscose fabric with nanoparticles was not done and microwave treatment were not performed. This matter will be referred to in this article.

\section{Experimental}

\section{Materials and methods}

In this study, polyester/viscose fabric, which is utilized to manufacture military costumes, with a ratio of $65 \%$ polyester and $35 \%$ viscose, a count of $32 / 2(\mathrm{Ne})$ warp and $32 / 1(\mathrm{Ne})$ weft and with a repeat of $2 / 1 z$ was used. Multi-wall carbon nanotubes and $\mathrm{Cu}$ nanoparticles were purchased from Sigma Aldrich. Acetic acid from Merck, a German Company and the dispersant material Ekalin F from Sandoz (Holzkirchen: Germany) were used in this study.

\section{Alkaline treatment}

The fabrics were washed in a batch consisting of $10 \%$ o.w.f. $\mathrm{Na}_{2} \mathrm{~S}_{2} \mathrm{O}_{4}$ at $70{ }^{\circ} \mathrm{C}$ and $10 \%$ o.w.f. $\mathrm{NaOH}$ for $30 \mathrm{~min}$.

\section{Microwave test}

The samples were placed in a household microwave oven (LG Electronics CG-2872BC 230 V, 50 Hz MAX.2400 W manufactured by LG Electronics Inc.) for 4, 8 and $12 \mathrm{~min}$ (back and front of the fabric) at 900 watts under microwave radiation, to absorb more nanoparticles and create pores on the surface images of scanning electron microscope (SEM) showed that by increasing the duration to $8 \mathrm{~min}$, the surface turns porous and creates a sponge-like condition, which by increasing the duration to $12 \mathrm{~min}$, causes the destruction of the fibers (Fig. 1).

\section{BET test}

The Brunauer-Emmett-Teller method (BET) has a wide utilization in the materials science to compute the solids surface areas through the physical absorption of gas molecules. Nitrogen adsorption (Micromeritics Gemini III 2375, USA) has been used to evaluate the BET surface area. This test was also carried out for radiation to prove the previous stage. 


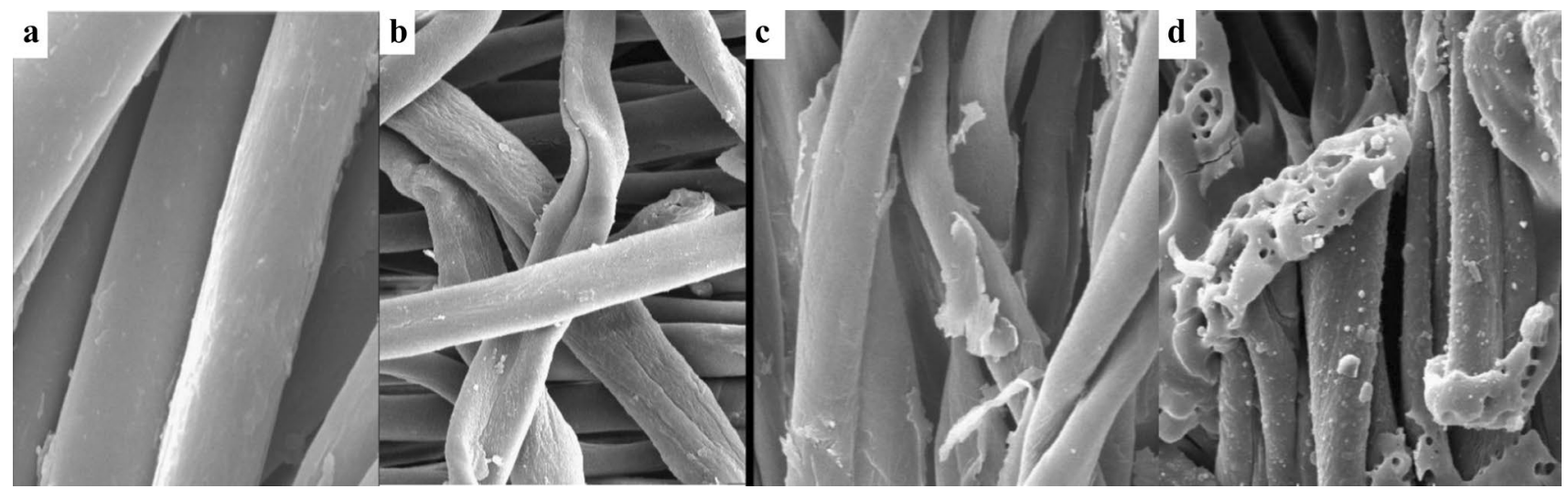

Fig. 1 Image of SEM samples of the fabric under microwave treatment in: a raw (2500×), b $4 \min (2500 \times)$, c $8 \min (2500 \times)$, d 12 min $(2500 \times)$

\section{Measuring the bending lengths and tensile strength}

Based on the ASTM D1388-96, Drapometer M003B (SDL) has been used to determine the fabrics bending length in the weft and warp directions. It should be noted that the fabrics tensile strength has been evaluated after conditioning the specimen at $20^{\circ} \mathrm{C}$ for $24 \mathrm{~h}$, with $65 \%$ relative humidity via an Instron TE-500 from Farayab through a 20-cm scale and across-head speed of $25 \mathrm{~cm} / \mathrm{min}$ (ASTM D2256).

\section{Determining the moisture regain}

Equation 1 has been used to calculate the moisture regain based on the ASTM procedure 2654-76:

Moisture regain $=\left\{\left[\left(W_{1}-W_{2}\right)\right] / W_{2}\right\} \times 100$.

Here, $W_{1}$ refers to the sample weight (g) following the saturation at the standard humidity. Moreover, $W_{2}$ represents the sample weight (g) dried to the constant weight.

\section{Colorimetry analysis}

According to the research design, a Gretagmacbeth COLOREYE 7000A spectro-photometer integrated with a computer has been used to determine the CIELAB color coordinates $\left(L^{*}, a^{*}, \& b^{*}\right)$ of the samples. Then, we computed the CIELAB color coordinates $\left(L^{*}, a^{*}, \& b^{*}\right)$ from the reflectance outputs for illuminant $\mathrm{D}_{65}$ and $10^{\circ}$ observer.

\section{SEM study}

Notably, a SEM (LEO1455VP), made in England, was used in order to investigate the surface morphology of the fiber.

\section{Treatment with nanoparticles}

In this stage, we procured the mixes consisting of different contents of nanoparticles $(3,5,7$ and $9 \%$ one weight of fabric (o.w.f.)), $10 \%$ o.w.f. dispersing agent, and $2 \%$ o.w.f. acetic acid. Afterwards, we added the fabrics into the mixes and inserted them in the bath of the dyeing machine. It is notable that the temperature, pressure, and duration, respectively, have been adjusted at $100{ }^{\circ} \mathrm{C}, 7 \mathrm{bar}$, and $90 \mathrm{~min}$. Of course, the liquor ratio $(L: R)$ is $50: 1$ and Ekalin $\mathrm{F}$ from Sandoz Company (Holzkirchen: Germany) was used as the dispersing agent.

\section{Washing procedure}

The fabrics have been washed in a bath consisting of $3 \%$ o.w.f. $\mathrm{NaOH}$ and $5 \%$ o.w.f. non-ionic detergent at $60{ }^{\circ} \mathrm{C}$ for $30 \mathrm{~min}$. Then the washing process was continued for 5 cycles.

\section{Conductivity test}

(a) The room-temperature conductivity of the samples has been gauged based on the standard four-probe procedure through a MCP-HT450 conductivity meter (Diainstruments Co., Ltd.).

(b) A digital multimeter has been used to determine the electrical conductivity of the composite of the dried fabrics has been specified at the room temperature $\left(25^{\circ} \mathrm{C}\right)$. Then, an electrical circuit manufactured by a Hewlett Packard 6634B System DC Power Supply and a digital Hewlett Packard 34401A Multimeter have been used to record the electrical measurements.

(c) Electro-chemical experiments have been performed on the CHI430a electro-chemical work station (USA) with a traditional 3-electrode system. 


\section{FTIR spectroscopy}

We used FTIR spectroscopy (Thermo Nicolet NEXUS 870 FTIR from Nicolet Instrument Corp., USA) to examine the samples FTIR spectra.

\section{Design of experimental}

We applied the central composite design (CCD) for the experimental program with two variables [29]. In fact, the variables involved the amount of irradiation time and percentage of nanoparticles. Results showed the variables range: irradiation time (4.8-12 $\mathrm{min})$ and percentage of nanoparticles (3.1-8.9\%), by means of the trial version of the Design Expert 8.0.1.0 software from the Stat-Ease, Inc. (USA).

Tables 7 and 8 (runs 1-8) report designing the polyester/ viscose fabric samples with the irradiation time and percentage of NPs in detail. Moreover, the variables influences on the outputs $Y_{1}$ (electrical resistivity) and $Y_{2}$ (surface resistance) have been tuned by the third-order poly-nominal function below (Eq. 2). It should be noted that although the specimens were selected to three series of time under the radiation but the softness of analyze the range of the changes was selected randomly, in the range of 4-12 min of radiation, and showed in eight different runs. On the other hand, laboratory experiments were carried out on the samples with four repeats.

$$
\begin{aligned}
& Y=b_{0}+\sum b_{i} X_{i}+\sum b_{i j} X_{i} X_{j}+\sum c_{i} X_{i}^{2} i \geq j \\
& i, j=1,2,3
\end{aligned}
$$

Here, $b_{0}$ represents an independent term based on the mean value of the experimental plan. $b_{\mathrm{i}}$ refers to the regression coefficients, which explain the variables impacts in their linear form. $b_{\mathrm{ij}}$ stands for the regression coefficients of the interaction terms between the variables. $c_{i}$ represents the coefficients of the variables quadratic form.

\section{Results and discussion}

Before the samples were treated with nanoparticles, they first were operated on under microwave irradiation [16] for different durations. The optimal mode for treating the surface of the fabric with nanoparticles was selected, which was found to be 8-min irradiation duration [based on the results of SEM images (Fig. 1)]. It should be noted that the highest percentage of degradation was in the viscose fiber, and the polyester fibers had a better resistance to microwave waves, which indicates that the results of the microscopic projection and the amount of nanoparticles remaining on the fiber surface after the operation of the washing, followed
Table 1 BET test values for raw and microwave-operated samples

\begin{tabular}{llccc}
\hline $\begin{array}{l}\text { Time of radiation } \\
(\mathrm{min})\end{array}$ & $\mathbf{0}$ & $\mathbf{4}$ & $\mathbf{8}$ & $\mathbf{1 2}$ \\
\hline BET & 4.11 & 4.28 & 4.86 & 2.89 \\
$V_{\mathrm{m}}$ & 0.506 & 0.521 & 0.582 & 0.355 \\
$C$ & 21.526 & 35.365 & 29.748 & 42.752 \\
\hline
\end{tabular}

$V_{\mathrm{m}}$ is the monolayer adsorbed gas quantity and $c$ is the BET constant

Table 2 Measurement strength and moisture regain test of microwave specimens

\begin{tabular}{lrrrr}
\hline Time of radiation (min) & \multicolumn{1}{c}{ Raw } & \multicolumn{1}{l}{4} & \multicolumn{1}{l}{12} \\
\hline Force at break (kg f) & 22.13 & 20.32 & 16.11 & 11.54 \\
Elongation at break (kg f) & 7.78 & 7.97 & 8.75 & 7.83 \\
Bending length—warp (cm) & 5.84 & 5.18 & 4.88 & 5.36 \\
Bending length-weft (cm) & 5.24 & 5.02 & 4.57 & 5.17 \\
Moisture regain (\%) & 7.21 & 7.85 & 8.23 & 7.05 \\
\hline
\end{tabular}

by absorption nanoparticles, are due to the further degradation viscose fibers in comparison with polyester fibers. As shown in Table 1, it is clear that BET values increased with increasing the radiation time. This increase from $8 \mathrm{~min}$ of radiation to $12 \mathrm{~min}$ caused decline in the surface area, indicating destruction of the fibers and them getting stuck together. On the other hand, according to the values given in Table 2, it is clear that the strength of the fabrics diminished by irradiation. The magnitude of the increase in length and the degree of rupture after irradiation increased until 8 min of irradiation and after that decreased. The reduction of strength can be due to the formation of pores on the fibers surfaces. Creation of pores also increased absorption of moisture in the sample. This increase in recycled moisture caused a plasticization phenomenon to occur, and increased the length of the rupture.

Images of the SEM fabric containing nanoparticles (Figs. 2, 3) show that for both nanotubes of CNTs and $\mathrm{Cu}$, increasing the amount of nanoparticles to 7 and $9 \%$ by weight resulted in the appearance of some NPs on the fiber surface, the presence of which is a lot more at the $9 \%$. In the less than 7\% amounts used, the nanoparticles were predominantly contained within the fiber. Particles on the surface usually decrease in their final washings (Figs. 2, 3). The results of strength measurement for $\mathrm{CNT}_{\mathrm{S}}$, also showed that the nanoparticles used at the $7 \%$ scale were at best, whereas for $\mathrm{Cu}$, with the increase of nanoparticles, the strength fell gradually (Table 3 ) which is in line with the work done by other scholars [30]. Also, the proposed mechanism for MWCNT and $\mathrm{Cu}$ nanoarticles on P/V Fiber indicated to Schemes 1 and 2. 


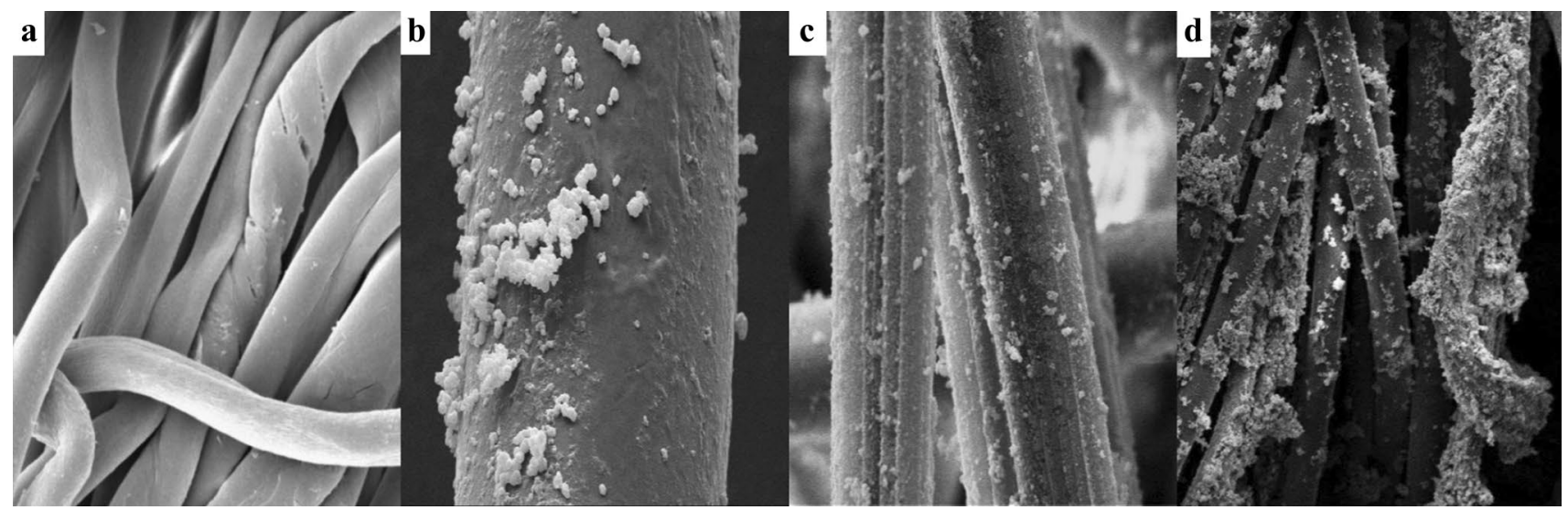

Fig. 2 Image of SEM samples of the fabric under 8-min microwave treatment in: a CNT 3\% o.w.f. (2000×), b CNT 5\% o.w.f. (5000×), c CNT $7 \%$ o.w.f. $(5000 \times)$, d CNT $9 \%$ o.w.f (500×)
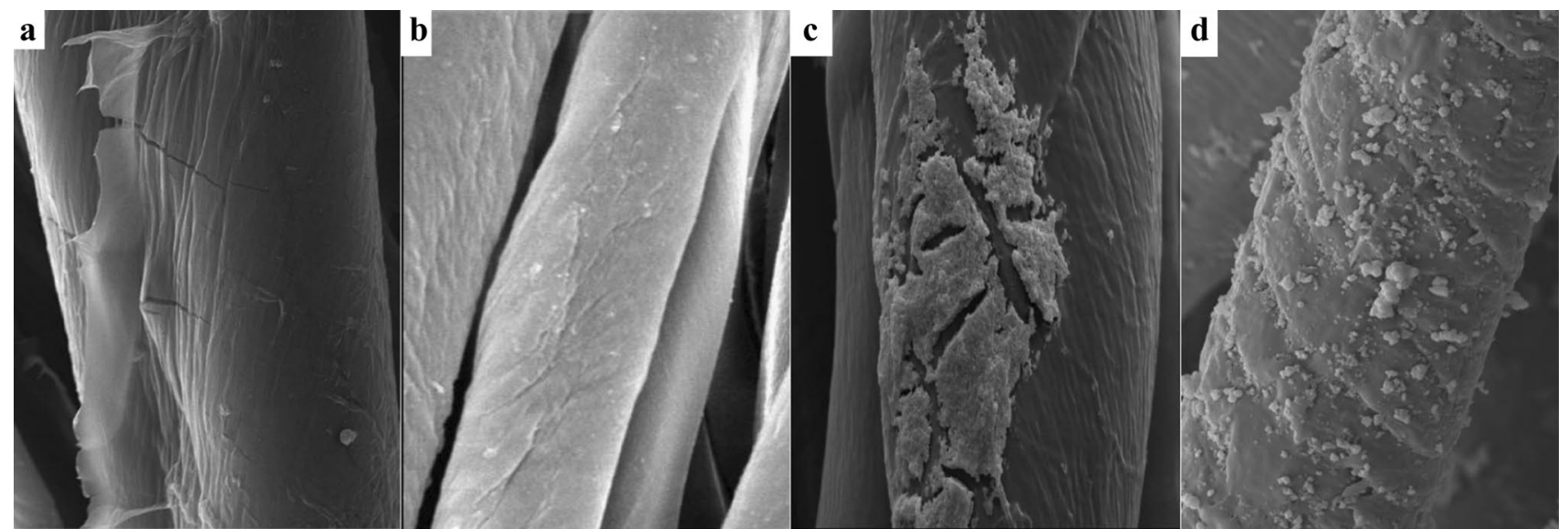

Fig. 3 Image of SEM samples of the fabric under 8-min microwave treatment in: a Cu 3\% o.w.f (5000×), b Cu 5\% o.w.f (2000×), c Cu 7\% o.w.f $(5000 \times)$, d Cu $9 \%$ o.w.f $(5000 \times)$

Table 3 Measurement strength test of microwave specimens in 8 min with different amounts of nanoparticles

\begin{tabular}{|c|c|c|c|c|c|c|c|c|}
\hline \multirow{2}{*}{$\begin{array}{l}\text { Nanoparticles value (\%) } \\
\text { Typical of nanoparticle }\end{array}$} & \multicolumn{2}{|l|}{3} & \multicolumn{2}{|l|}{5} & \multicolumn{2}{|l|}{7} & \multicolumn{2}{|l|}{9} \\
\hline & CNT & $\mathrm{Cu}$ & CNT & $\mathrm{Cu}$ & CNT & $\mathrm{Cu}$ & CNT & $\mathrm{Cu}$ \\
\hline Force at break (kg f) & 22.63 & 18.41 & 23.15 & 15.11 & 24.28 & 11.25 & 12.02 & 7.37 \\
\hline Elongation at break (\%) & 7.12 & 7.97 & 6.98 & 8.28 & 6.56 & 8.78 & 7.67 & 9.16 \\
\hline Bending length—warp $(\mathrm{cm})$ & 6.11 & 5.32 & 6.58 & 5.11 & 6.01 & 4.89 & 5.12 & 4.28 \\
\hline Bending length-weft $(\mathrm{cm})$ & 5.98 & 5.18 & 6.25 & 5.06 & 5.48 & 4.62 & 4.89 & 4.13 \\
\hline
\end{tabular}

Table 4 indicates the rate of washing stability for fabrics treated with nanoparticles. The results showed an increase in $\mathrm{Cu}$ uptake, compared to $\mathrm{CNT}_{\mathrm{S}}$ in the fabric, and higher fiber penetration of $\mathrm{Cu}$ nanoparticles than that of other nanoparticles this method has not been observed by others.

Moreover, the conductivity test was carried out in three ways: At first, the electrical resistance of the fabric was measured using a digital multimeter, the results of which are given in Table 5. In another way, the conductivity testing of nanoparticles treated with a digital multimeter and a DC voltage source under the AATCC 1995-76 Method at $25^{\circ} \mathrm{C}$ was carried out. In this approach, two copper electrodes with a size of $\left(20 \times 20 \mathrm{~mm}^{2}\right)$ were separated at a distance of $20 \mathrm{~mm}$, and then, a $1 \mathrm{~kg}$ weight was inserted over the fabric sample $\left(30 \times 60 \mathrm{~mm}^{2}\right)$. Afterwards, the surface resistance $\left(\mathrm{R}_{\mathrm{s}}\right)$ was estimated by Eq. 3: 
Scheme 1 The proposed mechanism of MWCNT on P/V Fiber

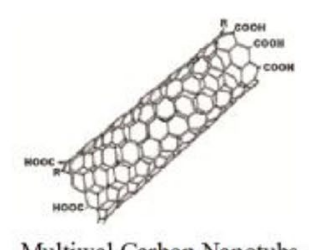

Multiwal Carbon Nanotubs

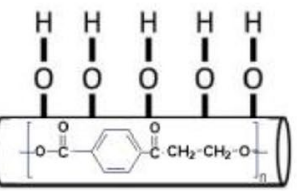

Polyester / Viscose fiber
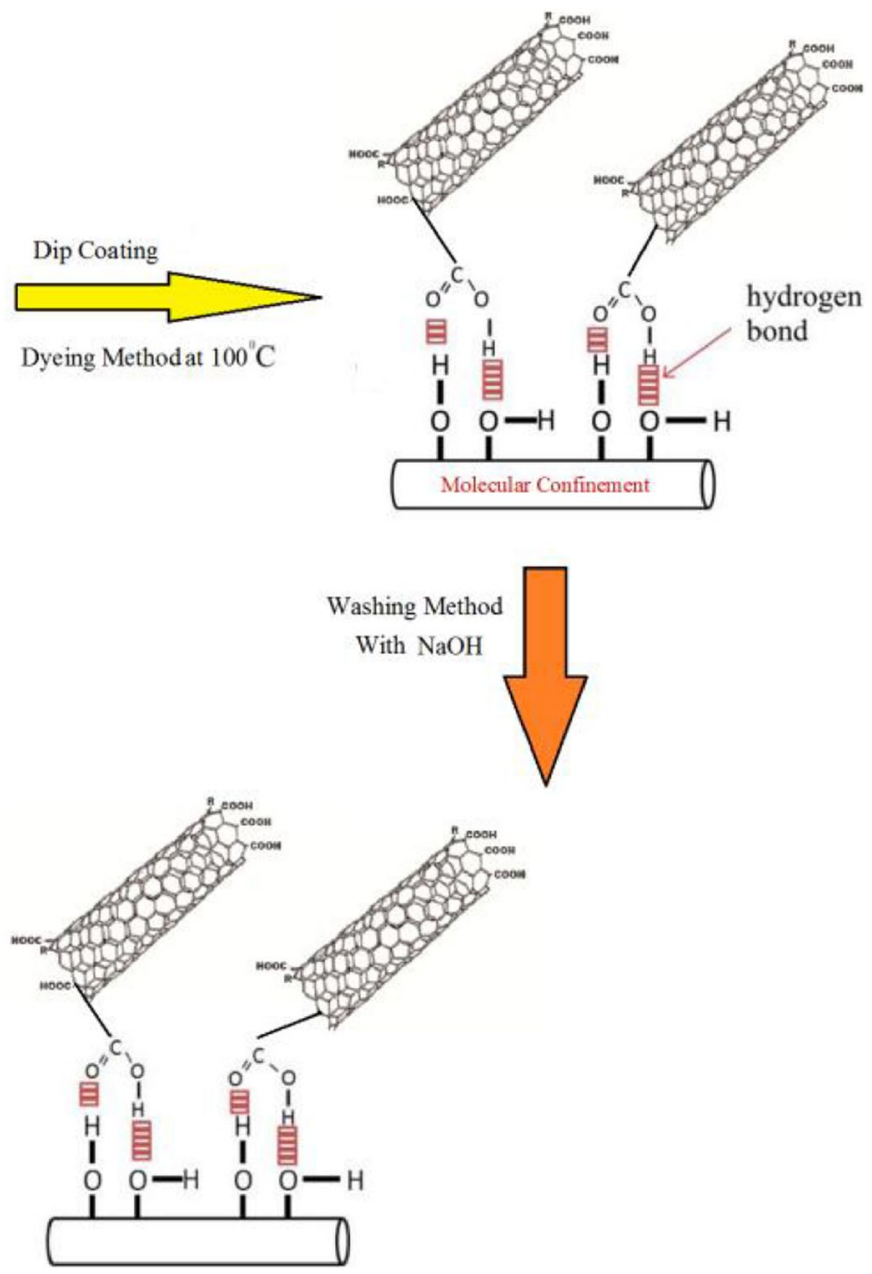

$R_{\mathrm{S}}(\Omega /$ square $)=(W / D) \times R$.

Here, $R$ represents the resistance gauged by the multimeter. $D$ and $W$, respectively, refer to the distance between 2 electrodes and sample width.

As shown in Table 5, the best electrical resistance is observed in the amounts of $9 \%$ consumable nanoparticles. Furthermore, at 3\%, electrical resistance for CNTS dropped, suddenly, however, a similarity was observed at $9 \%$ and 5\% nanoparticles. Moreover, the resulted quantities indicated an upward trend in conductivity. However, in $\mathrm{Cu}$ nanoparticles, there was an increase in conductivity up to $7 \%$, in comparison with $\mathrm{CNT}_{\mathrm{S}}$. On the other hand, the results showed the superiority of surface strength carbon nanotubes compared to $\mathrm{Cu}$ nanoparticles. The values of the electrical conductivity obtained are compared with those of other researchers in Table 13 [23-27].

In the third step, the conductivity of fabric treated with nanoparticles was measured using a CHI430A electro-chemical work station (USA), which has a three electrode system involving an auxiliary electrode (platinum wire), a reference electrode $(\mathrm{Ag} / \mathrm{AgCl})$, and working electrode (modified GCE). We conducted each experiment at room temperature. Then, we applied the cyclic voltammetry $(\mathrm{CV})$ to describe the electrode resistance functions. Afterwards, $5 \mathrm{mM}[\mathrm{Fe}$ $\left.(\mathrm{CN})_{6}\right]^{3-14-}$ has been employed as the probe, and $0.1 \mathrm{M} \mathrm{KCl}$ has been applied as the supporting electrolyte. The results of the test of the conductivity (flow-to-voltage) of the microwave treated samples, for a duration of $8 \mathrm{~min}$, for different voltammetric nanoparticles are shown in Figs. 4 and 5. Figures 4 and 5 show a comparison diagram of the ratio of the voltage intensity to the current of the samples treated with different nanoparticles, compared to the untreated sample with the nanoparticles after microwave operation (8 $\mathrm{min}$.). As shown in the plots, the difference is increased by increasing the percentage of nanoparticles. On the other hand, this difference in the samples treated by CNT has a special regularly compared to $\mathrm{Cu}$-treated samples, which seems to indicate the conductivity quality. 
Scheme 2 The proposed mechanism of MWCNT on P/V Fiber
Table 4 Measurement of the stability of the washing of the fabrics treated with nanoparticles
Table 5 Electrical resistivity and conductivity of a sample of fabrics under 8 min of microwave irradiation treated with MWCNT and $\mathrm{Cu}$ nanoparticles
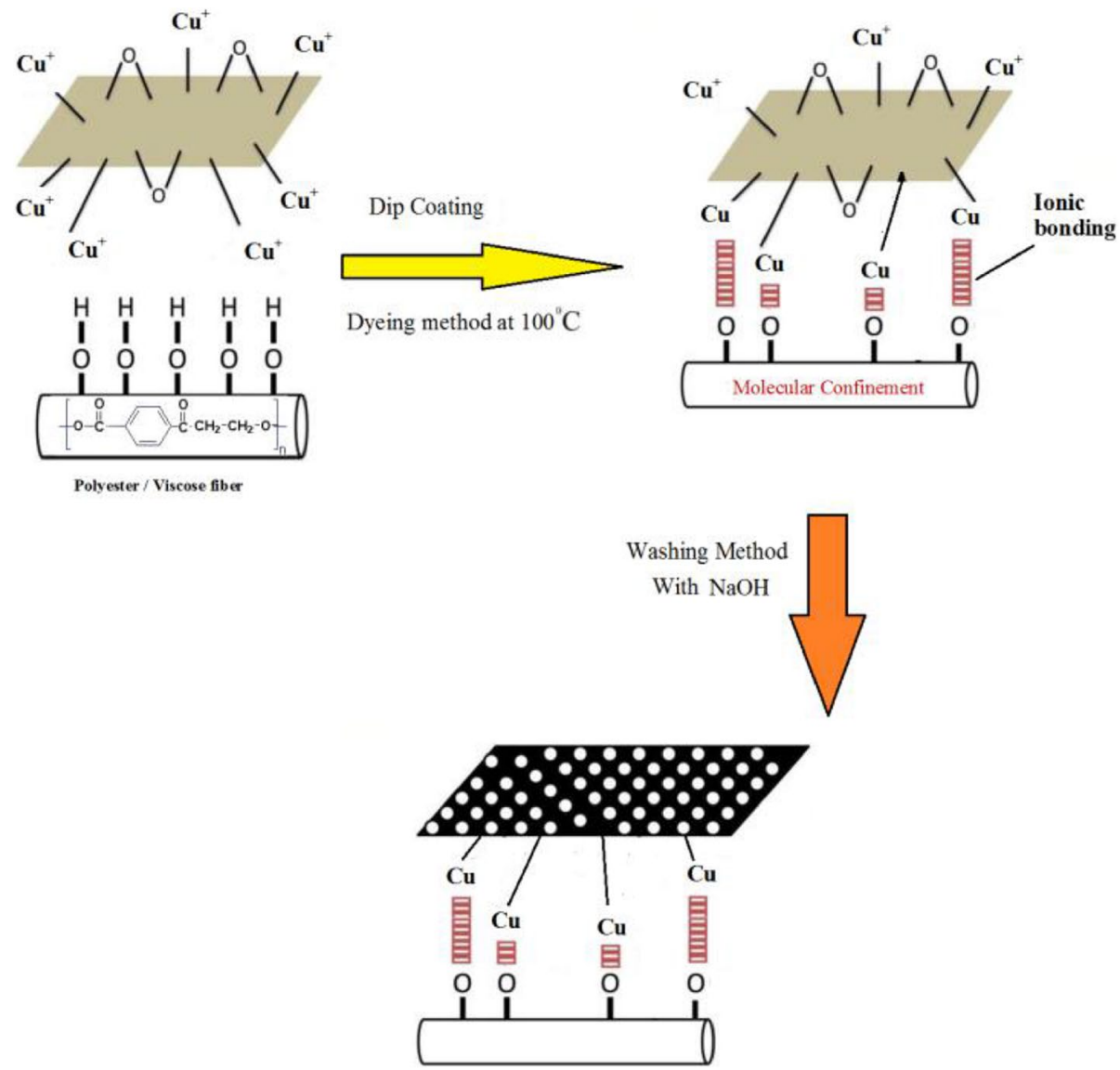

\begin{tabular}{|c|c|c|c|c|c|c|c|c|}
\hline \multirow{2}{*}{$\begin{array}{l}\text { Nanoparticles value (\%) } \\
\text { Typical of nanoparticle }\end{array}$} & \multicolumn{2}{|l|}{3} & \multicolumn{2}{|l|}{5} & \multicolumn{2}{|l|}{7} & \multicolumn{2}{|l|}{9} \\
\hline & CNT & $\mathrm{Cu}$ & CNT & $\mathrm{Cu}$ & CNT & $\mathrm{Cu}$ & CNT & $\mathrm{Cu}$ \\
\hline$R(\Omega)$ & 131251 & 26677 & 10368 & 10352 & 5369 & 2672 & 1610 & 1753 \\
\hline$\sigma(\mathrm{S} / \mathrm{cm})$ & 0.0023 & 0.0133 & 0.0247 & 0.0261 & 0.0651 & 0.1338 & 0.2335 & 0.3402 \\
\hline
\end{tabular}

Also, as shown in Table 6 , the $K / S$-values of the samples augmented by increasing the percentage of nanoparticles and decreased the $R \%$ values. However, it can be observed that there are similarities between the numerical values of $K / S$ and $R \%$ and samples treated with $9 \%$ nanoparticles for MWCNT and 7\% nanoparticles for $\mathrm{Cu}$, respectively; this is the equivalent of the coefficient equal to the propagation of samples. On the other hand, with respect to the values in the table, the values of $L^{*}, C$ and $h^{\circ}$ decreased with increasing the nanoparticle contents, and the values of $b^{*}$ decreased with increasing the amount of nanoparticles for $\mathrm{Cu}$ and for MWCNT, it firstly rose and then fell, steadily.

The FTIR spectra of samples are shown in Fig. 6. For the raw sample, the appeared bands at 3431, 2964, 2340, 

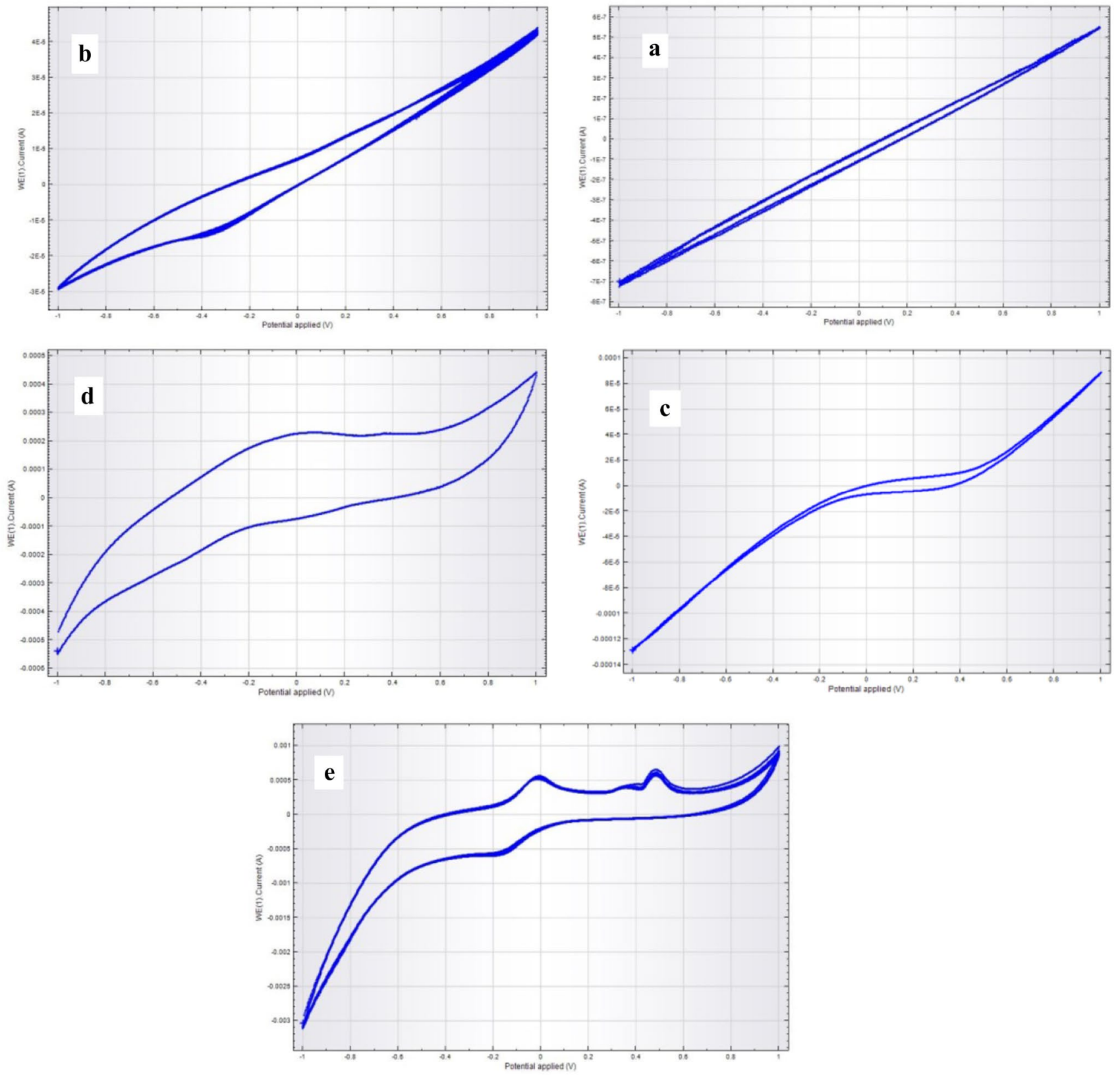

Fig. 4 Flow rate diagram of the voltages of the samples exposed to microwave radiation for 8 min for: a untreated, b $3 \% \mathrm{Cu}, \mathbf{c} 5 \% \mathrm{Cu}, \mathbf{d ~} 7 \% \mathrm{Cu}$, e $9 \% \mathrm{Cu}$

1715-1736, 1408, 1233,1000-1100 and 690-900 $\mathrm{cm}^{-1}$ were attributed to $\mathrm{OH}$ (H-bonded), aldehyde, carboxylic acids, $\mathrm{C}=\mathrm{O}, \mathrm{C}=\mathrm{C}$ (aromatic), $\mathrm{C}-\mathrm{H}$ bending, $\mathrm{C}-\mathrm{O}$ (esters or ethers) and aromatics (out of plane bend), respectively (Fig. 6a); whereas, in the sample treated with MWCNTs the bands observed at 3446, 2913,1640, 1000-1100 and $690-900 \mathrm{~cm}^{-1}$ related to $\mathrm{OH}$ (H-bonded), aldehyde, $\mathrm{C}=\mathrm{C}$ (aromatic), $\mathrm{C}-\mathrm{O}$ (esters or ethers) and aromatics (out of plane bend), respectively (Fig. 6b). Moreover, in Fig. 6c, the sample treated with $\mathrm{Cu}$ nanoparticles indicated approximately the same results. As shown in Figs. 7 and 8, the decrease in the peak intensity of carboxylic acid groups $\left(2362 \mathrm{~cm}^{-1}\right)$ is caused by the existence of the Cu NPs and MWCNTs onto the fabrics. On the other hand, the peak appearing in $1417 \mathrm{~cm}^{-1}$ related to MWCNTs [28] and the peaks appearing $592 \mathrm{~cm}^{-1}$ and $500 \mathrm{~cm}^{-1}$ attributed to $\mathrm{Cu}$ nanoparticles [29].

\section{Statistical analyses}

Based on the analyses, optimizing the use of the NPs would suggest the fundamental contribution to the outperformance 

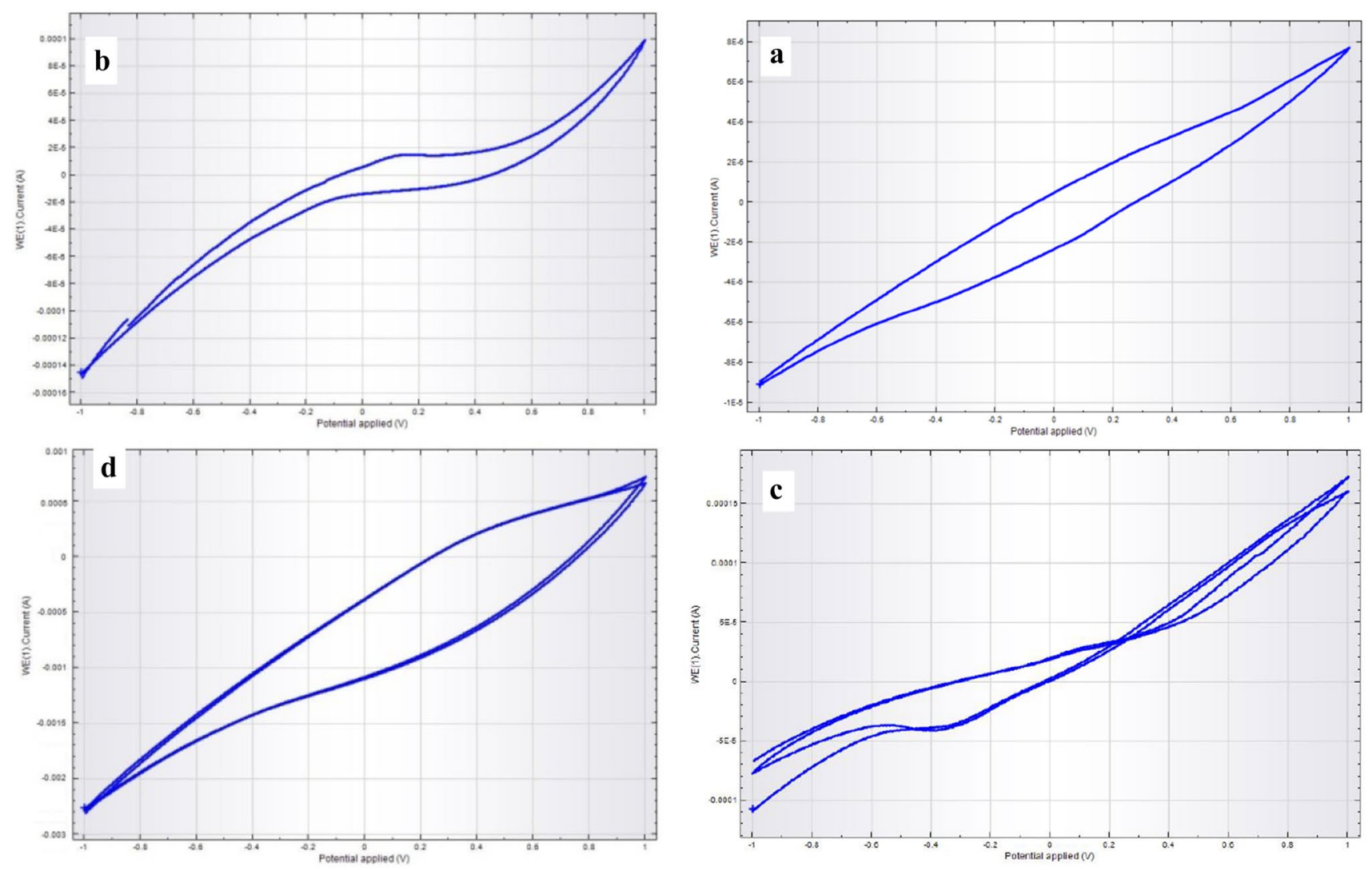

Fig. 5 Flow rate diagram of the voltages of the samples exposed to microwave radiation for 8 min for: a 3\% CNT, b 5\% CNT, c 7\% CNT, d 9\% CNT

Table $6 \mathrm{~K} / \mathrm{S}, \% R$, CIELab and CIEch values of samples of microwave-irradiated fabrics for 8 min under treatment of MWCNT and $\mathrm{Cu}$ nanoparticles

\begin{tabular}{lllrrrr}
\hline Nanoparticles value $(\%)$ & & Raw & \multicolumn{1}{l}{3} & \multicolumn{1}{l}{5} & \multicolumn{1}{l}{7} \\
\hline$K / S\left(\lambda_{\max }=400 \mathrm{~nm}\right)$ & MWCNT & 0.068 & 4.9 & 5.94 & 9.916 & \multicolumn{1}{l}{10.9} \\
& Cu & & 6.9 & 7.93 & 11.05 & 12.14 \\
& MWCNT & 84.34 & 14.87 & 9.88 & 6.87 & 5.84 \\
& Cu & & 16.71 & 11.73 & 6.88 & 5.82 \\
$L^{*}$ & MWCNT & 92.49 & 44.82 & 36.82 & 30.33 & 29.21 \\
& Cu & & 38.51 & 30.53 & 27.34 & 25.26 \\
$a^{*}$ & MWCNT & -0.32 & 3.12 & 2.87 & 2.02 & 2.01 \\
& Cu & & 2.59 & 2.59 & 2.42 & 2.31 \\
$b^{*}$ & MWCNT & 4.12 & 7.52 & 6.88 & 5.35 & 5.42 \\
& Cu & & 3.25 & 3.08 & 2.95 & 2.91 \\
$C$ & MWCNT & 4.13 & 6.69 & 5.25 & 4.86 & 4.67 \\
& Cu & & 6.99 & 4.19 & 3.82 & 3.49 \\
$h^{\circ}$ & MWCNT & 94.45 & 74.17 & 69.91 & 61.36 & 57.62 \\
& Cu & & 64.29 & 52.69 & 50.65 & 47.57 \\
\hline
\end{tabular}




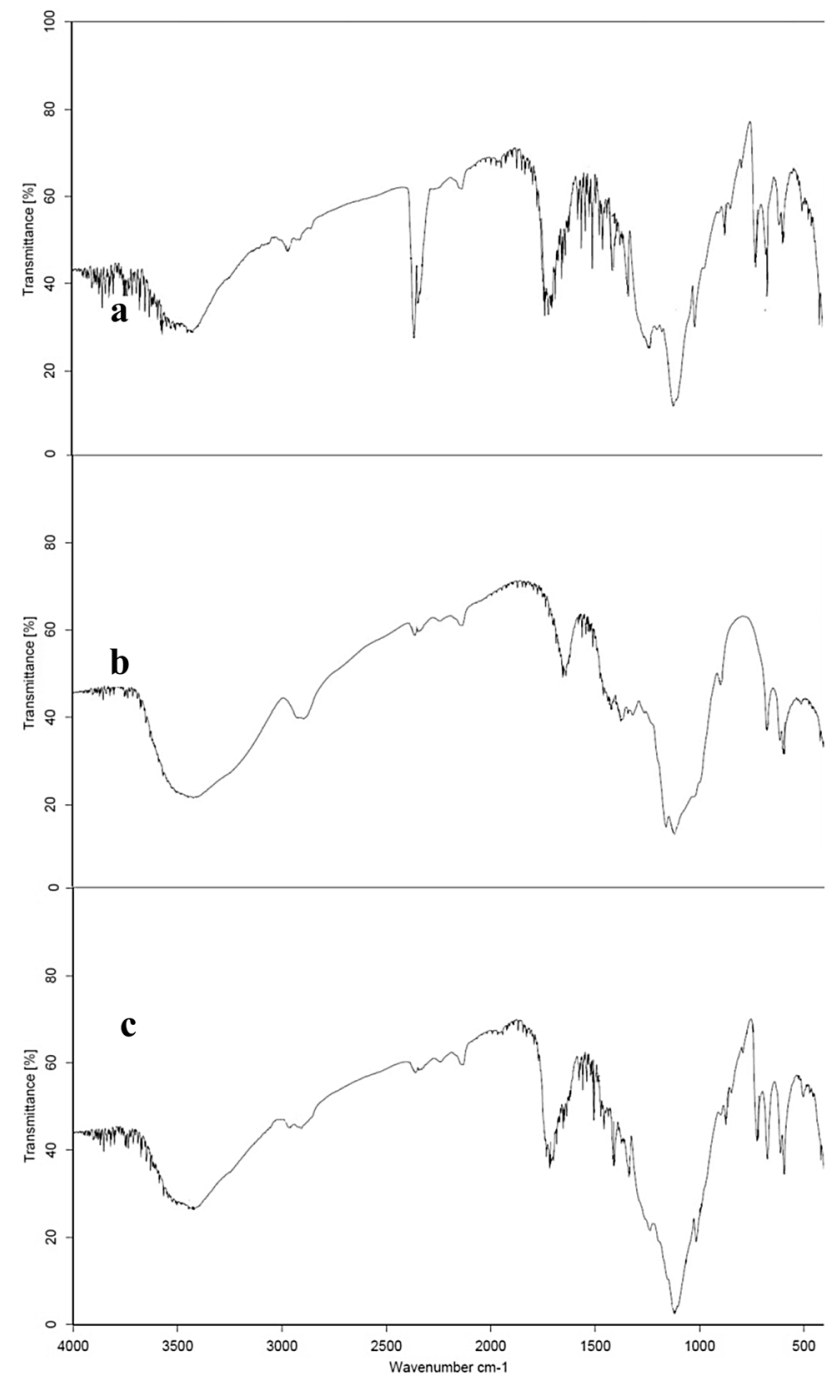

Fig. 6 ATR-FTIR analyses of polyester/viscose blend fabric: a raw sample, b sample of microwave-irradiated fabrics for 8 min under treatment of MWCNT, $\mathbf{c}$ sample of microwave-irradiated fabrics for 8 min under treatment of $\mathrm{Cu}$ nanoparticles

of the textile fabrics. Here, it should be noted that contrary to the traditional optimization, the statistical optimization procedures and interactions between variables for production of the procedure response may be considered. In fact, RSM is one of the robust statistical techniques of analyzing several variables as a result of fewer essential experimental trials in comparison with the "one-factor-at-a-time" technique. Moreover, RSM is one of the effective mathematical approaches of optimization of the complicated procedures that are able to produce an empirical pattern for evaluating the correlation between some controlled experimental parameters and the observed outputs. Actually, RSM is widely employed in different biochemical, nano-chemical, and chemical procedures for analyzing the effects of the independent variables and optimizing the procedure responses via the suitable values of the parameters [18-22]. The present research was carried out on the basis of the CCD and RSM. Eight experimental CCD designed runs have been accomplished, as demonstrated by Tables 7 and 8 . As seen, the impacts of the independent variables like the irradiation time and nanoparticles percentage on the response surface have been evaluated. This justified the electrical resistivity and conductivity properties of treated fabric samples.

Final equation in terms of actual factors related to electrical resistivity and conductivity of the sample of fabrics treated with $\mathrm{Cu}$ nanoparticles and $\mathrm{MWCNT}_{\mathrm{S}}$ are presented in Eqs. (4), (5), (6) and (7), respectively:

$$
\begin{aligned}
R(\Omega)= & +96540.82306-6820.09154 \times \text { irradiation time } \\
& -12668.11108 \times \mathrm{Cu} \text { nanoparticle }+945.36356 \\
& \times \text { irradiation time } \times \mathrm{Cu} \text { nanoparticle },
\end{aligned}
$$

$$
\begin{aligned}
\sigma(\mathrm{S} / \mathrm{cm})= & -0.681510+0.054816 \times \text { irradiation time } \\
& +0.152864 \times \mathrm{Cu} \text { nanoparticle }-0.011227 \\
& \times \text { irradiation time } \times \mathrm{Cu} \text { nanoparticle }
\end{aligned}
$$

$$
\begin{aligned}
& R(\Omega)=+6.92 \times 10^{5}-49574.332 \times \text { irradiation time }-1.303 \\
& \times 10^{5} \times \text { CNT nanoparticle }+2927.025 \\
& \times \text { irradiation time } \times \text { CNT nanoparticle }+1649.91 \\
& \times \text { irradiation time }^{2}+6906.983 \times \text { CNT nanoparticle } \\
&
\end{aligned}
$$

$$
\begin{aligned}
\sigma(S / \mathrm{cm})= & +0.067-0.0287 \times \text { irradiation time }-0.000051 \\
& \times \text { CNT nanoparticle }-0.0061 \times \text { irradiation time } \\
& \times \text { CNT nanoparticle }+0.00355 \times \text { irradiation time }^{2} \\
& +0.0076 \times \text { CNT nanoparticle }
\end{aligned}
$$

The resulting statistical models have been used to draw the response surface (Eqs. 4-7), and then, the relationship between all independent variables as well as electrical resistivity and conductivity of fabric specimens have been achieved. Figures 7 and 8, respectively, depict the response surface of the fabric samples.

In the next stage, Design-Expert software, with irradiation time of 8 min for both $\mathrm{Cu}$ nanoparticles and CNT has been used to obtain the optimal conditions of the properties of electrical resistivity and conductivity of fabric specimens. Then, analysis of variance (ANOVA) has been applied for analyzing the data so that the interactions between independent variables and responses have been established. Afterwards, ANOVA 

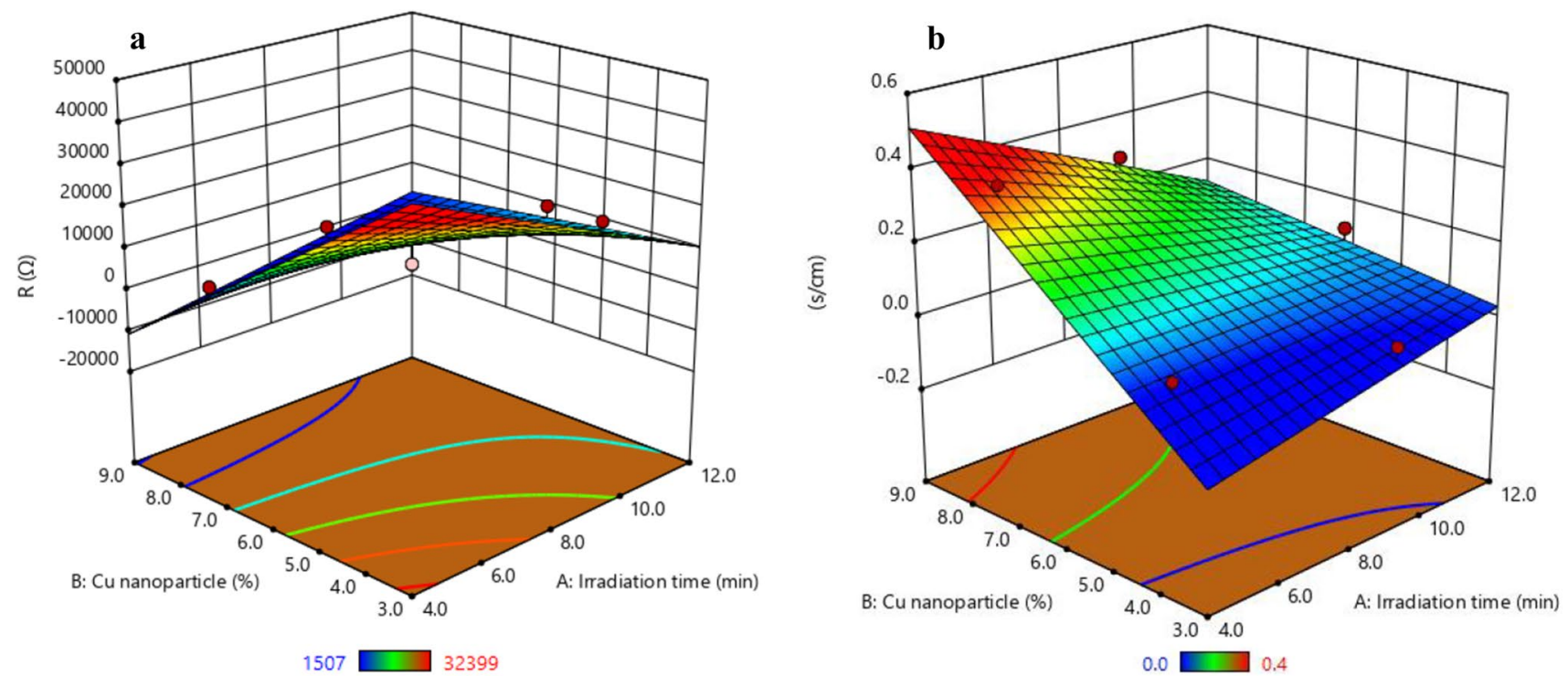

Fig. 7 Response surface for a electrical resistivity and $\mathbf{b}$ conductivity as a function of irradiation time and $\mathrm{Cu}$ nanoparticles for fabric samples
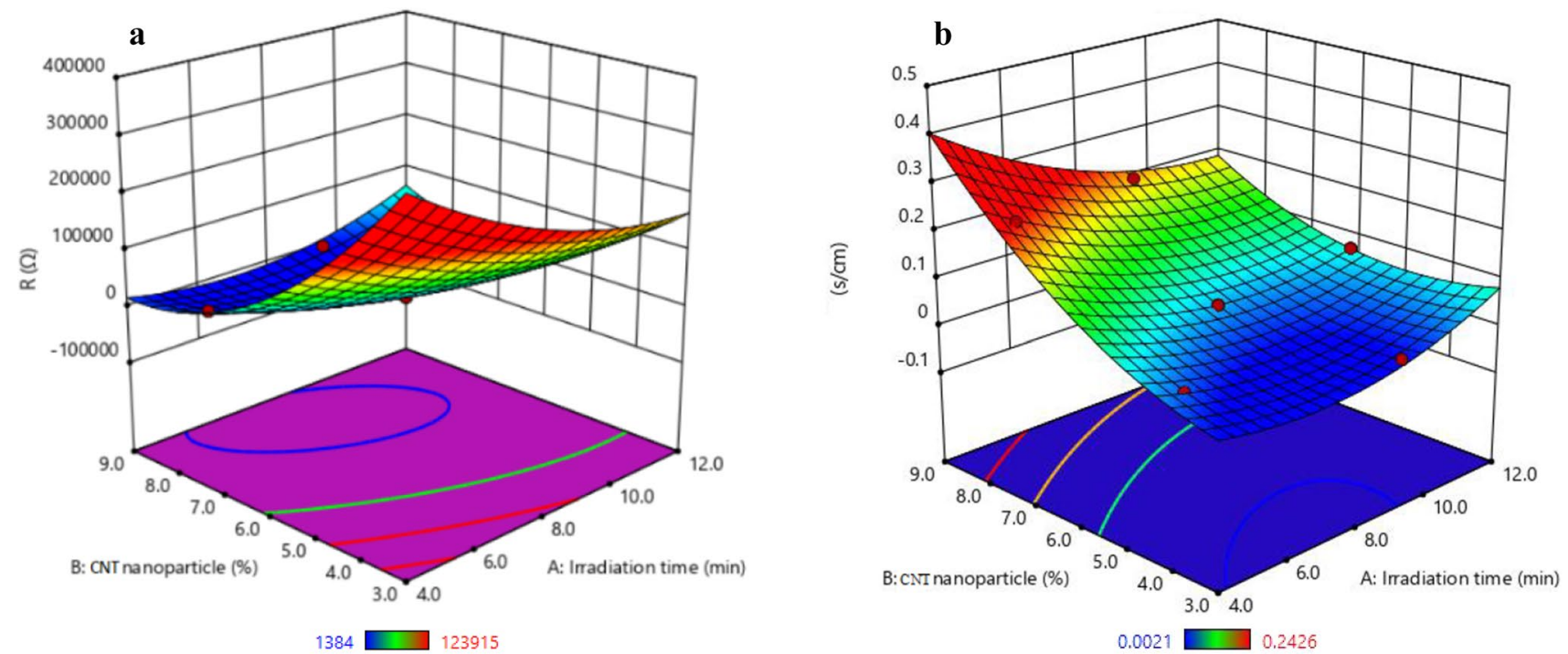

Fig. 8 Response surface for $\mathbf{a}$ electrical resistivity and $\mathbf{b}$ conductivity as a function of irradiation time and CNT nanoparticles for fabric samples 
Table 7 CCD for electrical resistivity and conductivity of sample of fabrics treated with $\mathrm{Cu}$ nanoparticles at different irradiation times

\begin{tabular}{llllll}
\hline Run & Factor & & & \multicolumn{2}{l}{ Responses } \\
\cline { 2 - 3 } \cline { 5 - 6 } & $\begin{array}{l}\text { Irradiation } \\
\text { time (min) }\end{array}$ & $\begin{array}{l}\text { Go-nanopar- } \\
\text { ticle }(\%)\end{array}$ & $\mathrm{R}(\Omega)$ & $\sigma(\mathrm{S} / \mathrm{cm})$ \\
\hline Control 1 & 0 & 6 & 74652 & 0.0015 \\
Control 2 & 8 & 0 & Unlimited & Unlimited \\
1 & 8 & 6 & 6550 & 0.07943 \\
2 & 8 & 6 & 6512 & 0.07995 \\
3 & 8 & 6 & 6490 & 0.07894 \\
4 & 4.8 & 4.2 & 32399 & 0.0345 \\
5 & 4.8 & 7.8 & 3595 & 0.3851 \\
6 & 12 & 6 & 9768 & 0.1199 \\
7 & 9.2 & 8.9 & 1507 & 0.2925 \\
8 & 9.2 & 3.1 & 23970 & 0.01195 \\
\hline
\end{tabular}

Table 8 CCD for electrical resistivity and conductivity of sample of fabrics treated with $\mathrm{MWCNT}_{\mathrm{S}}$ at different irradiation times

\begin{tabular}{llllll}
\hline Run & \multicolumn{2}{l}{ Factor } & & \multicolumn{2}{l}{ Responses } \\
\cline { 2 - 3 } \cline { 5 - 6 } & $\begin{array}{l}\text { Irradiation } \\
\text { time (min) }\end{array}$ & $\begin{array}{l}\text { CNT-nano- } \\
\text { particle }(\%)\end{array}$ & $R(\Omega)$ & $\sigma(\mathrm{S} / \mathrm{cm})$ \\
\hline Control 1 & 0 & 6 & 163257 & 0.003 \\
Control 2 & 8 & 0 & Unlimited & Unlimited \\
1 & 8 & 6 & 7868 & 0.0449 \\
2 & 8 & 6 & 7810 & 0.0457 \\
3 & 8 & 6 & 7895 & 0.0436 \\
4 & 4.8 & 4.2 & 123915 & 0.0236 \\
5 & 4.8 & 7.8 & 5671 & 0.2426 \\
6 & 12 & 6 & 11802 & 0.0674 \\
7 & 9.2 & 8.9 & 1384 & 0.2008 \\
8 & 9.2 & 3.1 & 117936 & 0.0021 \\
\hline
\end{tabular}

has been used to analyze the outputs in order to evaluate the electrical resistivity and conductivity of the fabric samples (Tables 9, 10, 11, 12).

As shown, the introduced model of the fabric samples with $\mathrm{Cu}$ nanoparticles and $\mathrm{MWCNT}_{\mathrm{S}}$ for electrical resistivity has been statistically significant at $F$ value of 8.56 and $2.070 \mathrm{E}+06$, and prob values greater than $F, 0.0325$ and $<0.0001$, respectively (Tables 9,11 ). In addition, the selected model of the treated fabric specimens with $\mathrm{Cu}$ nanoparticles and MWCNTS for conductivity has been significant at $F$ value of 9.54 and 9623.67 and prob values greater than $F, 0.0270$ and $<0.0001$, respectively (Tables 10,12 ).

\section{Comparison of electrical conductivity results with previous results}

Also, Table 13 shows the comparative results of the electrical conductivity obtained with the results obtained in previous papers.

\section{Conclusion}

The effects of nanoparticles (MWCNT and $\mathrm{Cu}$ ) treatment on the conductivity of the polyester/viscose fabric were investigated and their benefit demonstrated. Studies using SEM, conductivity test, electrical resistance, strength and voltametric charts of the fabric have shown that under optimal microwave pre-radiation conditions, sample treated with MWCNT and $\mathrm{Cu}$ nanoparticles exhibited improved conductivity. Statistical results using the central composite design (CCD) methodology further established that the fabric samples treated with MWCNT nanoparticles had better uniformity and higher conductivity compared with that treated with $\mathrm{Cu}$ nanoparticles.
Table 9 ANOVA outputs of electrical resistivity for the fabric samples with $\mathrm{Cu}$ nanoparticles at different irradiation times

\begin{tabular}{llllrrl}
\hline Source & Sum of squares & $d f$ & Mean square & $F$ value & $p$ value & Probability $>F$ \\
\hline Model & $7.198 \mathrm{E}+08$ & 3 & $2.399 \mathrm{E}+08$ & 8.56 & 0.0325 & Significant \\
A-irradiation time & $5.271 \mathrm{E}+07$ & 1 & $5.271 \mathrm{E}+07$ & 1.88 & 0.2421 & \\
B-Cu nanoparticle & $5.865 \mathrm{E}+08$ & 1 & $5.865 \mathrm{E}+08$ & 20.93 & 0.0102 & \\
AB & $8.047 \mathrm{E}+07$ & 1 & $8.047 \mathrm{E}+07$ & 2.87 & 0.1654 & \\
Residual & $1.121 \mathrm{E}+08$ & 4 & $2.802 \mathrm{E}+07$ & & & \\
Lack of fit & $1.121 \mathrm{E}+08$ & 2 & $5.604 \mathrm{E}+07$ & 60865.70 & $<0.0001$ & Significant \\
Pure error & 1842.67 & 2 & 921.33 & & & \\
Cor total & $8.319 \mathrm{E}+08$ & 7 & & & & \\
\hline
\end{tabular}


Table 10 ANOVA outputs of conductivity for the fabric samples with $\mathrm{Cu}$ nanoparticles at different irradiation times
Table 11 ANOVA outputs of electrical resistivity for the fabric samples with MWCNT $_{\mathrm{S}}$ at different irradiation times
Table 12 ANOVA outputs of conductivity for the fabric samples with $\mathrm{MWCNT}_{\mathrm{S}}$ at different irradiation times

\begin{tabular}{llllrrl}
\hline Source & Sum of squares & $d f$ & Mean square & $F$ value & $p$ value & Probability $>F$ \\
\hline Model & 0.1071 & 3 & 0.0357 & 9.54 & 0.0270 & Significant \\
A-irradiation time & 0.0063 & 1 & 0.0063 & 1.68 & 0.2643 & \\
B-Cu nanoparticle & 0.0894 & 1 & 0.0894 & 23.89 & 0.0081 & \\
AB & 0.0113 & 1 & 0.0113 & 3.03 & 0.1566 & \\
Residual & 0.0150 & 4 & 0.0037 & & & \\
Lack of fit & 0.0150 & 2 & 0.0075 & 29347.65 & $<0.0001$ & Significant \\
Pure error & $5.102 \mathrm{E}-07$ & 2 & $2.551 \mathrm{E}-07$ & & & \\
Cor total & 0.1221 & 7 & & & &
\end{tabular}

\begin{tabular}{lrrrrrr}
\hline Source & Sum of squares & $d f$ & Mean square & $F$ value & $p$ value & Probability $>F$ \\
\hline Model & $1.952 \mathrm{E}+10$ & 5 & $3.904 \mathrm{E}+09$ & $2.070 \mathrm{E}+06$ & $<0.0001$ & Significant \\
A-irradiation time & $1.260 \mathrm{E}+09$ & 1 & $1.260 \mathrm{E}+09$ & $6.682 \mathrm{E}+05$ & $<0.0001$ & \\
B-Cu nanoparticle & $1.301 \mathrm{E}+10$ & 1 & $1.301 \mathrm{E}+10$ & $6.896 \mathrm{E}+06$ & $<0.0001$ & \\
AB & $7.714 \mathrm{E}+08$ & 1 & $7.714 \mathrm{E}+08$ & $4.089 \mathrm{E}+05$ & $<0.0001$ & \\
Residual & $7.467 \mathrm{E}+08$ & 1 & $7.467 \mathrm{E}+08$ & $3.958 \mathrm{E}+05$ & $<0.0001$ & \\
Lack of fit & $4.140 \mathrm{E}+09$ & 1 & $4.140 \mathrm{E}+09$ & $2.195 \mathrm{E}+06$ & $<0.0001$ & \\
Pure error & 3772.67 & 2 & 1886.33 & & & \\
Cor total & $1.952 \mathrm{E}+10$ & 7 & & & & \\
\hline
\end{tabular}

\begin{tabular}{llllrrr}
\hline Source & Sum of squares & $d f$ & Mean square & $F$ value & $p$ value & Probability $>F$ \\
\hline Model & 0.0541 & 5 & 0.0108 & 9623.67 & 0.0001 & Significant \\
A-irradiation time & 0.0029 & 1 & 0.0029 & 2586.67 & 0.0004 & \\
B-Cu nanoparticle & 0.0404 & 1 & 0.0404 & 35936.37 & $<0.0001$ & \\
AB & 0.0033 & 1 & 0.0033 & 2976.53 & 0.0003 & \\
Residual & 0.0035 & 1 & 0.0035 & 3072.84 & 0.0003 & \\
Lack of fit & 0.0050 & 1 & 0.0050 & 4457.50 & 0.0002 & \\
Pure error & $2.247 \mathrm{E}-06$ & 2 & $1.123 \mathrm{E}-06$ & & & \\
Cor total & 0.0541 & 7 & & & & \\
\hline
\end{tabular}

Table 13 Comparison of results with those reported in previously published

\begin{tabular}{|c|c|c|c|c|c|c|c|}
\hline Type of goods & $\begin{array}{l}\text { Optimum sample } \\
\text { PV-MWCNT } \\
\text { Irradiation time: } \\
9.2 \\
\text { (\% 8.9 o.w.f) }\end{array}$ & $\begin{array}{l}\text { Optimum sample } \\
\text { PV-Cu } \\
\text { Irradiation time: } \\
9.2 \\
\text { (\% 8.9 o.w.f) }\end{array}$ & $\begin{array}{l}\text { Wool-MWCNT } \\
(5.5 \mathrm{~g} / \mathrm{L}) \\
{[23]}\end{array}$ & $\begin{array}{l}\text { Aminolyzed } \\
\text { polyester-\% } 0.2 \\
\text { GO } \\
{[24]}\end{array}$ & $\begin{array}{l}\text { Nylon-nano- } \\
\text { silver } \\
{[25]}\end{array}$ & $\begin{array}{l}\text { Polyester- } \\
\text { MWCNT } \\
(30 \mathrm{~g} / \mathrm{L}) \\
{[26]}\end{array}$ & $\begin{array}{l}\text { Cotton-GO } \\
1 \%[27]\end{array}$ \\
\hline $\mathrm{R}(\Omega / \mathrm{Sq})$ & 1384 & 1507 & $1.07 \times 10^{7}$ & $0.11 \times 10^{6}$ & 4.5 & $10^{3}$ to $10^{9}$ & 55 \\
\hline
\end{tabular}

Open Access This article is distributed under the terms of the Creative Commons Attribution 4.0 International License (http://creativeco mmons.org/licenses/by/4.0/), which permits unrestricted use, distribution, and reproduction in any medium, provided you give appropriate credit to the original author(s) and the source, provide a link to the Creative Commons license, and indicate if changes were made.

\section{References}

1. Sedighi, Ali, Montazer, Majid, Mazinani, Saeedeh: Fabrication of electrically conductive superparamagnetic fabric with microwave attenuation, antibacterial properties and UV protection using PEDOT/magnetite nanoparticles. Mater. Des. 160, 34-47 (2018)

2. Stoppa, M., Chiolerio, A.: Wearable electronics and smart textiles: a critical review. Sensors 14(7), 11957-11992 (2014) 
3. Huang, Y., Hu, H.: Y Huang from industrially wearable and knittable highly conductive yarns to large wearable energy storage textiles. ACS Nano. 9(5), 4766-4775 (2015)

4. Asif, A.K., Hasan, M.Z.: Application of nanotechnology in modern textiles. Int. J. Curr. Eng. Technol. 8(2), 227-231 (2018)

5. Musante, C., White, J.C.: Toxicity of silver and copper to Cucurbitapepo: differential effects of nano and bulk-size particles. Environ. Toxicol. 27(9), 510-517 (2012)

6. Gokarneshan, N., Naren, G.: Some significant trends in conductive textiles. Trends Text. Fash Design 2(3), 179-186 (2018)

7. Bhattacharyya, A., Joshi, M.: Development of polyurethane based conducting nanocomposite fibers via twin screw extrusion. Fibers Polym. 12, 734-740 (2011)

8. Kaynak, A., Najar, S.S., Foitzik, R.C.: Conducting nylon, cotton and wool yarns by continuous vapor polymerization of pyrrole. Synth. Met. 158, 1-5 (2008)

9. Molina, J., Fernández, J., del Río, A.I., Lapuente, R., Bonastre, J., Cases, F.: Stability of conducting polyester/polypyrrole fabrics in different pH solutions. Chem. Electrochem. Char. Polym. Degrad. Stab. 95, 2574-2583 (2010)

10. Molina, J., Fernández, J., del Río, A.I., Bonastre, J., Cases, F.: Chemical, electrical and electrochemical characterization of hybrid organic/inorganic polypyrrole/PW12O403_ coating deposited on polyester fabrics. Appl. Surf. Sci. 257, 10056-10064 (2011)

11. Rakshit, A.K., Hira, M.A.: Electrically conductive fibre substrates. International Journal of Fiber and Textile Research 4(3), 44-48 (2014)

12. Kozio, K., Vilatela, J., Moisala, A., Motta, M., Cunniff, P., Sennett, M., et al.: High-performance carbon nanotubes fiber. Science 318, 1892-1896 (2007)

13. Fugetsua, Bunshi, Akiba, Eiji, Hachiya, Masaaki, Endo, Morinobu: The production of soft, durable, and electrically conductive polyester multifilament yarns by dye-printing them with carbon nanotubes. Carbon 47, 527-544 (2009)

14. Ali, A., Nguyen, N.H., Baheti, V., Ashraf, M., Militky, J., Mansoor, T., Noman, M.T., Ahmad, S.: Electrical conductivity and physiological comfort of silver coated cotton fabrics. J Text Inst 109, 1-9 (2017)

15. Ebrahimbeiki Chimeh, A., Montazer, M., Rashidi, A.: Conductive and photoactive properties of polyethylene terephthalate fabrics treated with nano $\mathrm{TiO}_{2} /$ nano carbon blacks. New Carbon Mater. 28(4), 313-320 (2013)

16. Peng, Linghui, Guo, Ronghui, Lan, Jianwu, Jiang, Shouxiang: Microwave-assisted deposition of silver nanoparticles on bamboo pulp fabric through dopamine functionalization. Appl. Surf. Sci. 386, 151-159 (2016)

17. Abou Elmaaty, T., Abdelaziz, E., Nasser, D., Abdelfattah, K., Elkadi, S., El-Nagar, K.: Microwave and nanotechnology advanced solutions to improve eco-friendly cotton's coloration and performance properties. Egypt. J. Chem. 61(3), 493-502 (2018)
18. Nazari, A., Montazer, M., Mirjalili, M., Nazari, S.: Polyester with durable uv protection properties through using nano $\mathrm{TiO}_{2}$ and polysiloxane softener optimized by RSM. J. Text. Inst. 104, 511-520 (2013)

19. Zarrinabadi, Ehsan, Abghari, Ramin, Nazari, Ali, Mirjalili, Mohammad: Environmental effects of enhancement of mechanical and hydrophobic properties of polyester fabrics using silica/ kaolinite/silver nanocomposite: a facile technique for synthesis and RSM optimization. Eurasia J Biosci 12, 1-14 (2018)

20. Qi, B., Chen, X., Shen, F., Su, Y.: Optimization of enzymatic hydrolysis of wheat straw pretreated by alkaline peroxide using response surface methodology. Ind. Eng. Chem. Res. 48, 73467353 (2009)

21. Tatineni, R., Doddapaneni, K.K., Potumarthi, R.C., Mangamoori, L.: N, Optimization of keratinase production and enzyme activity using response surface methodology with streptomyces sp7. Appl. Biochem. Biotechnol. 141, 187-201 (2007)

22. Zhong, K., Wang, Q.: Optimization of ultrasonic extraction of polysaccharides from dried longan pulp using response surface methodology. Carbohyd. Polym. 80, 10-25 (2010)

23. Montazer, M., Ghayem Asghari, M.S., Pakdel, E.: Electrical conductivity of single walled and multiwalled carbon nanotube containing wool fibers. J. Appl. Polym. Sci. 121, 3353-3358 (2011)

24. Zhang, Y., Wang, S., Li, L., Zhang, K., Qiu, J., Davis, M., HopeWeeks, L.J.: Mater. Chem. Phys. 135, 1057 (2012)

25. Montazer, M., Komeily Nia, Z.: Conductive nylon fabric through in situ synthesis of nano-silver: preparation and characterization. Sci. Direct Mater. Sci. Eng. C 56, 341-347 (2015)

26. Fugetsu, Bunshi, Akiba, Eiji, Hachiya, Masaaki, Endo, Morinobu: The production of soft, durable, and electrically conductive polyester multifilament yarns by dye-printing them with carbon nanotubes. Sci. Direct, CARBON 47, 527-554 (2009)

27. Sahito, I.A., Sun, K.C., Arbab, A.A., Qadir, M.B., Jeong, S.H.: Graphene coated cotton fabric as textile structured counter electrode for DSSC. Sci Direct Electrochimica Acta 173, 164-171 (2015)

28. Misra, A., Tyagi, P.K., Rai, P., Misra, D.S.: FTIR spectroscopy of multiwalled carbon nanotubes; a simple approach to study the nitrogen doping. J. Nanosci. Nanotechnol. 7(6), 1820-1823 (2007)

29. Nyguist, R.A., Kagel, R.O.: Handbook of Infrared and Raman spectra of inorganic compounds and organic salt: Infrared spectra of inorganic compounds. Academic press, Cambridge (2012)

30. Sedighi, A., Montazer, M., Hemmatinejad, N.: Copper nanoparticles on bleached cotton fabric: in situ Synthesis and characterization. Cellulose 21, 2119-2132 (2014)

Publisher's Note Springer Nature remains neutral with regard to jurisdictional claims in published maps and institutional affiliations. 